\title{
Characterization of aqueous phase from the hydrothermal liquefaction of Chlorella pyrenoidosa
}

\author{
Chao Gai ${ }^{\mathrm{a}}$, Yuanhui Zhang ${ }^{\mathrm{b}, *}$, Wan-Ting Chen ${ }^{\mathrm{b}}$, Yan Zhou ${ }^{\mathrm{b}}$, Lance Schideman ${ }^{\mathrm{b}}$, Peng Zhang ${ }^{\mathrm{b}}$, \\ Giovana Tommaso $^{\mathrm{b}, \mathrm{c}}$, Chih-Ting Kuo ${ }^{\mathrm{b}}$, Yuping Dong ${ }^{\mathrm{d}}$ \\ ${ }^{a}$ Research Center for Eco-Environmental Sciences, Chinese Academy of Sciences, 18 Shuangqing Road, Beijing 100085, PR China \\ ${ }^{\mathrm{b}}$ Department of Agricultural and Biological Engineering, University of Illinois at Urbana-Champaign, Urbana, IL 61801, USA \\ ${ }^{c}$ Laboratory of Environmental Biotechnology, Department of Food Engineering, University of Sao Paulo, 225, Duque de Caxias Norte, Pirassununga, Sao Paulo 13635-900, Brazil \\ ${ }^{\mathrm{d}}$ Key Laboratory of High Efficiency and Clean Mechanical Manufacture, Department of Mechanical Engineering, Shandong University, Jinan 250061, PR China
}

\section{H I G H L I G H T S}

- Hydrothermal liquefaction of low-lipid microalgae C. pyrenoidosa.

- Response surface method was used to design the whole experiments.

- Interactions of operation conditions on concentration of nutrients of aqueous phase.

- Major chemical compositions of the three aqueous phase samples were determined.

\section{A R T I C L E I N F O}

\section{Article history:}

Received 18 August 2014

Received in revised form 22 October 2014

Accepted 24 October 2014

Available online 6 November 2014

\section{Keywords:}

Low-lipid algae

Hydrothermal liquefaction

Aqueous product

Nutrient

Nitrogen recovery

\begin{abstract}
A B S T R A C T
This study investigated the characteristics of aqueous phase from hydrothermal liquefaction of low-lipid microalgae Chlorella pyrenoidosa. The interactions of operating conditions, including reaction temperature, retention time and total solid ratio were evaluated by response surface methodology. The chemical oxygen demand, total nitrogen and total phosphorus were selected as indicators of the property of AP. Results indicated that total solid ratio was found to be the dominant factor affecting the nutrient recovery efficiencies of AP. Based on energy recovery, GC-MS indicated that the AP at two optimized operating conditions $\left(280^{\circ} \mathrm{C}, 60 \mathrm{~min}, 35 \mathrm{wt} . \%\right.$ and $\left.300^{\circ} \mathrm{C}, 60 \mathrm{~min}, 25 \mathrm{wt} . \%\right)$ were observed to have a higher concentration of organic acids ( $10.35 \%$ and $8.34 \%$ ) while the sample $\left(260{ }^{\circ} \mathrm{C}, 30 \mathrm{~min}, 35 \mathrm{wt} . \%\right)$ was observed to have the highest concentration of N\&O-heterocyclic compounds (36.16\%).
\end{abstract}

(c) 2014 Elsevier Ltd. All rights reserved.

\section{Introduction}

Microalgae has emerged as a promising feedstock for biofuel production via hydrothermal technologies (Biller and Ross, 2011; Ross et al., 2010; Scholz et al., 2013). This method is the chemical and physical transformations of microalgae in high-temperature $\left(200-600^{\circ} \mathrm{C}\right)$ and high-pressure $(5-40 \mathrm{MPa})$ liquids/water (Peterson et al., 2008), such as hydrothermal carbonization, hydrothermal gasification and hydrothermal liquefaction. Hydrothermal liquefaction (HTL) can convert organic substrates of the feedstock into bio-crude oil meanwhile a large amount of wastewater containing various nutrients is produced as a co-product in this

\footnotetext{
* Corresponding author at: 1304 W. Pennsylvania Avenue, Urbana, IL 61801, USA. Tel.: +1 217333 2693; fax: +1 2172440323.

E-mail address: yzhang1@illinois.edu (Y. Zhang).
}

process. To date, most studies focusing on HTL processing use lipid-rich microalgae as the feedstock (López Barreiro et al., 2013). Some recent studies have verified that other microalgae with lower lipid content but higher growth rates might constitute a suitable feedstock for this technology (Li et al., 2014; Gai et al., 2013).

Our previous study (Gai et al., 2014) carried out HTL experiments of low-lipid microalgae Chlorella pyrenoidosa and investigated the energy and nutrient recovery efficiencies in bio-crude oils. In addition, it demonstrated that during this process, around 10-50\% carbon and 50-70\% nitrogen from the feedstock was released into the aqueous phase (AP). The comparatively high level of carbon and nitrogen in the AP are generally unsuitable to be directly discharged to the environment without additional treatment (Anastasakis and Ross, 2011; Garcia Alba et al., 2013). Sending the organic and nutrient rich HTL AP back for algae cultivation can allow for multiple cycles of algal growth on each unit of 
incoming nutrient, thus maximizing bioenergy production per unit of nutrient input. This team dedicated to studying a novel system for biofuel production that synergistically integrates nutrient recycling for algae cultivation with HTL of microalgae into bio-crude oil, which is referred to as "Environment-Enhancing Energy ( $E^{2}$-Energy)". This approach has been discussed in detail in our previous publication (Yu et al., 2011a; Zhou et al., 2013; Gai et al., 2014; Chen et al., 2014a; Chen et al., 2014b). It showed that $E^{2}$-Energy can amplify the biomass and biofuel production from wastewater by up to 10 times, which gives it the potential to replace all U.S. petroleum imports using only current wastewater feedstocks and carbon dioxide from the atmosphere or point sources.

Although algal cultivation on HTL AP is the key step of achieving such huge potential in bioenergy production, the lack of understating on HTL AP composition is making the investigation on this essential step difficult to go to a more profound level. For example, several recent studies (Jena et al., 2011a; Biller et al., 2012) investigated on algal cultivation on HTL AP (mostly conversion of feedstock from a single operating condition) and found that the nutrient and organic concentrations in HTL AP significantly affect the algae growth. These studies also found that HTL AP has some inhibitory effect on algal growth probably due to some toxic organic compounds, and therefore various rates of dilution of HTL AP or further treatment is needed. Pham et al. (2013) found high inhibitory potential related to nitrogenous organic compounds in AP from HTL of microalgae Spirulina and observed that granular activated carbon was effective in removing the toxic effect from the effluent. These findings all leads to the questions including: what is the range of the organic and nutrient content/concentration in HTL AP? How much dilution will be needed for different HTL AP? What factors influence the nutrient and organic re-release into HTL AP? What are the potential organic component in HTL AP that has inhibitory effect on HTL AP and can we manipulate the HTL operation to avoid or minimize the formation of them? How can we optimize the HTL AP quality/composition to maximize the overall bioenergy condition? Which kind of treatment would be effective to promote such optimization? The answers to all these questions are related to the characterization of the aqueous product.

This study tries to promote the development of the novel nutrient recycling concept by first characterizing the HTL AP from Chlorella both from the aspects of bulk nutrient and organic composition, as well as detailed chemical composition analysis. In this study, chemical oxygen demand (COD), total nitrogen (TN) and total phosphorus (TP) were selected to evaluate the properties of AP. These parameters are the most commonly used parameters to characterize wastewater. In addition, they can represent the carbon/organic, nitrogen and phosphorus content in HTL AP, which are the significant nutrients for growth of algae. The main objective of this study was to investigate the effect of operation conditions and their interactions on the characteristics of AP obtained from HTL processing of low-lipid microalgae.

\section{Methods}

\subsection{Materials}

As a typical microalgal with low-lipid and high-protein content, C. pyrenoidosa is a spherical, eukaryotic and unicellular algae (Becker, 2007), which is cultured worldwide for foods and biofuels. It is a kind of algae with a higher biomass yield and can grow in harsher environments such as wastewater. In this study $C$. pyrenoidosa was obtained from a health-food store as food-grade material (NOW FOODS, Bloomingdale, IL). Elemental compositions of $C$. pyrenoidosa were determined by an elemental analyzer (CE-440, Exeter Analytical Inc., North Chelmsfor, MA). Macromolecular and chemical compositions were analyzed according to the standard methods of the Association of Official Analytical Chemists (AOAC). The proximate and ultimate analysis of the sample were shown in Table 1.

\subsection{Experimental design}

Compared to the approach of "one-factor-at-a-time", response surface methodology could investigate the interactions of different operating parameters on the variation of targets and get a perspective of the entire process, which was adopted in this study. The key variables affecting nutrient recovery during HTL processes, including reaction temperature, retention time and total solid ratio were selected as three independent factors in this study. Based on the results of preliminary single factor experiments (Yu, 2012), the levels of three operating parameters were determined in the range of $260-300{ }^{\circ} \mathrm{C}, 30-90 \mathrm{~min}$ and $15-35 \mathrm{wt} . \%$ for reaction temperature, retention time and total solid ratio, respectively. The response variables for AP were: chemical oxygen demand (COD), total nitrogen (TN) and total phosphorus (TP). A face-centered central composite design (FCCCD) was employed to design the experiment.

\subsection{Experimental procedure}

HTL experiments were carried out using stainless steel cylindrical reactors with $100 \mathrm{~mL}$ capacity (Model 4593, Parr Instrument Col, Moline, IL) with three replicates for each reaction condition. During each test, $70 \mathrm{~g}$ feedstock slurries were loaded into the reactor. Pure nitrogen gas was used to purge the reactor three times after the reactor was sealed. According to previous studies (Yu et al., 2011a), the initial pressure was set as $0.69 \mathrm{MPa}$ and each test was operated in subcritical pressure. The reactor was heated at a heating rate of around $6^{\circ} \mathrm{C} / \mathrm{min}$ by an electric heater up to a certain reaction temperature and maintained for a certain retention time according to the experimental design. The stirring rate was set as $300 \mathrm{rpm}$. Finally, the reactor was cooled to room temperature by flowing tap water through the cooling coil and it took about an hour to cool down. The recovery procedures for the HTL product streams, including gaseous, oils, aqueous and solid phase products were performed according to previously reported methods (Yu

Table 1

Characteristics of $C$. pyrenoidosa.

\begin{tabular}{|c|c|c|c|c|c|}
\hline \multicolumn{2}{|c|}{ Proximate analysis \% } & \multicolumn{2}{|c|}{ Chemical composition analysis (wt.\%) } & \multicolumn{2}{|c|}{ Elemental analysis (wt.\%) } \\
\hline Moisture (wt.\%) & 6.3 & Crude fat & 0.1 & $\mathrm{C}$ & 51 \\
\hline Dry solid (wt.\%) & 94 & Crude protein & 71 & $\mathrm{H}$ & 6.6 \\
\hline Volatile solid & 94 & Non-fibrous carbohydrate & 22 & $\mathrm{~N}$ & 11 \\
\hline Ash & 5.6 & Lignocellulose & 1.0 & $\mathrm{O}^{\mathrm{b}}$ & 31.4 \\
\hline
\end{tabular}

\footnotetext{
a On the total weight basis.
}

b Calculated by difference. 
et al., 2011a,b). The gas in the reactor was first sampled using a Tedlar $^{\circledR}$ gas sampling bag through a control valve, then analyzed by a gas chromatography (Varian CP-3800). Afterwards, the reactor was opened and the remaining mixture was separated. Raw oil products were separated from the aqueous phase by physical filtration. The solid residue fraction of the raw oil products was obtained via Soxhlet extraction using the solvent of toluene. The toluene soluble fraction of the raw oil product was defined as the bio-crude oils.

\subsection{Characterization}

The AP of HTL process were first filtered by $1-\mu \mathrm{m}$ pore size glass filter (Whatman, 1821-150) and stored at $4{ }^{\circ} \mathrm{C}$ for analysis. The chemical oxygen demand (COD) of AP was measured by visible light absorbance after dichromate digestion based on standard methods using a visible light spectrophotometer (HACH Model $\mathrm{DR} / 2010$ ). Total nitrogen was evaluated by the persulfate digestion method (HACH Method 10072). The chemical compositions of AP were analyzed using GC-MS (Agilent 7890A GC-5975C MS, Agilent Technologies, Santa Clara, CA) equipped with flame ionization detector (FID) and ZB-WAX column. The mass spectra was interpreted according to the NIST mass spectral database.

Phosphorus is an essential nutrient for algal cultivation. It is found in nucleic acids, lipids, proteins, and the intermediates of carbohydrate metabolism (Cai et al., 2013). Valdez et al. (2012) investigated the elemental distribution during HTL of Nannochloropsis sp. and they found that the values determined for total phosphorus and phosphate were similar. Garcia Alba et al. (2012) also reported that all phosphorus in the AP from the HTL of Desmodesmus sp. was in the form of phosphate. Therefore, it should be noted that in this study the total phosphorus was measured as total phosphate by performing the phosphate assay on AP because most of the phosphorus in the AP is present as free phosphate (i.e. $\mathrm{PO}_{4}^{3-}$ ), and it was determined adopting $\mathrm{HACH}$ method (HACH Method 10127).

\section{Results and discussion}

\subsection{Model fitting and statistical analysis}

Table 2 presents the design of experiments (DOE) and experimental results with average and standard deviations. Each test was repeated for three times. It can be seen that at different combinations of the operation conditions, COD of AP ranged from $6.27 \mathrm{E} 4 \pm 2.95 \mathrm{E} 3 \mathrm{mg} / \mathrm{L}$ to $1.04 \mathrm{E} 5 \pm 4.57 \mathrm{E} 3 \mathrm{mg} / \mathrm{L}$. TN varied between $1.10 \mathrm{E} 4 \pm 3.06 \mathrm{E} 2 \mathrm{mg} / \mathrm{L}$ and $3.17 \mathrm{E} 4 \pm 1.35 \mathrm{E} 3 \mathrm{mg} / \mathrm{L}$. TP ranged from $5.44 \mathrm{E} 3 \pm 2.55 \mathrm{E} 2 \mathrm{mg} / \mathrm{L}$ to $1.89 \mathrm{E} 4 \pm 9.15 \mathrm{E} 2 \mathrm{mg} / \mathrm{L}$.

Second-order polynomial regression equation was used to fit response surface models based on the experimental results, which is expressed as the following.

$y=\beta_{0}+\sum_{i=1}^{k} \beta_{i} x_{i}+\sum_{i=1}^{k} \beta_{i i} x_{i}^{2}+\sum_{i=1}^{k-1} \sum_{j=i+1}^{k} \beta_{i j} x_{i} x_{j}+\varepsilon$

where $y$ is the response variable; $\beta_{0}$ is the interception coefficient; $\beta_{i}$ is the first order quadratic model coefficient; $\beta_{i i}$ is the second order quadratic model coefficient; $\beta_{i j}$ is the linear model coefficient for the interaction between independent variables $i$ and $j$; $\varepsilon$ is the fitting error; $x_{i}$ and $x_{j}$ are the coded independent variables, which are calculated by the following equation.

$x_{\text {coded }, i}=\frac{2 x_{\text {actual }, i}-x_{\text {actual,max }}-x_{\text {actual,min }}}{x_{\text {actual,max }}-x_{\text {actual,min }}}$

where $x_{\text {actual }}$ and $x_{\text {coded }}$ are the actual and coded forms of the independent variable.

The developed models are evaluated using analysis of variance (ANOVA) to establish their statistical significance at a confidence level of $95 \%$. Table 3 shows the corresponding results of three tests of the models for the response variables, including the test of significance of model and terms, the test of lack of fit and the coefficient of the determination $\left(R^{2}\right)$ test.

The test of significance of the model and terms are evaluated by the $p$-value. It is the smallest level of significance that could be used to reject the null hypothesis. It can be seen from Table 3 that the $p$-values for all models are less than 0.05, which means the surface response models are statistically significant at the $95 \%$ confidence level. Table 3 also shows that different models have varied significant levels, which indicates that the nutrient recovery of AP are affected by different operating conditions and their interactions. The lack of fit test is used to evaluate the probability of the model failing to predict the experimental values due to the noise brought by systematic errors or other overlooked factors. It can be observed from Table 3 that the $p$-values for all the response models are higher than 0.05 , which indicates the lack of fit for all models is not significant. Therefore, the models are adequate and reliable. The coefficient of the determination test is applied to evaluate how well a model can predict the experimental results.

Table 2

FCCCD matrix of independent factors and response variables.

\begin{tabular}{|c|c|c|c|c|c|c|c|}
\hline Run No. & Point type & Reaction temperature $\left({ }^{\circ} \mathrm{C}\right)$ & Retention time (min) & Total solid ratio (wt.\%) & $\mathrm{COD}(\mathrm{mg} / \mathrm{L})$ & $\mathrm{TN}(\mathrm{mg} / \mathrm{L})$ & $\mathrm{TP}(\mathrm{mg} / \mathrm{L})$ \\
\hline 1 & Factorial & $260(-1)$ & $30(-1)$ & $15(-1)$ & $8.21 \mathrm{E} 4 \pm 3.92 \mathrm{E} 3$ & $1.17 \mathrm{E} 4 \pm 5.00 \mathrm{E} 2$ & $1.11 \mathrm{E} 4 \pm 5.15 \mathrm{E} 2$ \\
\hline 2 & Factorial & $260(-1)$ & $30(-1)$ & $35(+1)$ & $9.59 \mathrm{E} 4 \pm 3.79 \mathrm{E} 3$ & $2.68 \mathrm{E} 4 \pm 1.05 \mathrm{E} 3$ & $1.89 \mathrm{E} 4 \pm 9.15 \mathrm{E} 2$ \\
\hline 3 & Factorial & $260(-1)$ & $90(+1)$ & $15(-1)$ & $8.23 \mathrm{E} 4 \pm 3.11 \mathrm{E} 3$ & $1.67 \mathrm{E} 4 \pm 7.02 \mathrm{E} 2$ & $5.44 \mathrm{E} 3 \pm 2.55 \mathrm{E} 2$ \\
\hline 4 & Factorial & $260(-1)$ & $90(+1)$ & $35(+1)$ & $9.83 \mathrm{E} 4 \pm 4.41 \mathrm{E} 3$ & $3.17 \mathrm{E} 4 \pm 1.35 \mathrm{E} 3$ & $1.45 \mathrm{E} 4 \pm 6.85 \mathrm{E} 2$ \\
\hline 5 & Factorial & $300(+1)$ & $30(-1)$ & $15(-1)$ & $6.94 \mathrm{E} 4 \pm 2.96 \mathrm{E} 3$ & $1.45 \mathrm{E} 4 \pm 6.00 \mathrm{E} 2$ & $6.02 \mathrm{E} 3 \pm 2.80 \mathrm{E} 2$ \\
\hline 6 & Factorial & $300(+1)$ & $30(-1)$ & $35(+1)$ & $1.00 \mathrm{E} 5 \pm 4.09 \mathrm{E} 3$ & $2.53 \mathrm{E} 4 \pm 7.21 \mathrm{E} 2$ & $1.24 \mathrm{E} 4 \pm 5.35 \mathrm{E} 2$ \\
\hline 7 & Factorial & $300(+1)$ & $90(+1)$ & $15(-1)$ & $6.27 \mathrm{E} 4 \pm 2.95 \mathrm{E} 3$ & $1.10 \mathrm{E} 4 \pm 3.06 \mathrm{E} 2$ & $6.84 \mathrm{E} 3 \pm 3.15 \mathrm{E} 2$ \\
\hline 8 & Factorial & $300(+1)$ & $90(+1)$ & $35(+1)$ & $9.87 \mathrm{E} 4 \pm 3.96 \mathrm{E} 3$ & $2.27 \mathrm{E} 4 \pm 6.56 \mathrm{E} 2$ & $1.48 \mathrm{E} 4 \pm 5.30 \mathrm{E} 2$ \\
\hline 9 & Axial & $260(-1)$ & $60(0)$ & $25(0)$ & $9.76 \mathrm{E} 4 \pm 4.57 \mathrm{E} 3$ & $1.98 \mathrm{E} 4 \pm 7.09 \mathrm{E} 2$ & $8.16 \mathrm{E} 3 \pm 3.70 \mathrm{E} 2$ \\
\hline 10 & Axial & $300(+1)$ & $60(0)$ & $25(0)$ & $9.45 \mathrm{E} 4 \pm 4.35 \mathrm{E} 3$ & $1.63 \mathrm{E} 4 \pm 6.00 \mathrm{E} 2$ & $7.26 \mathrm{E} 3 \pm 3.55 \mathrm{E} 2$ \\
\hline 11 & Axial & $280(0)$ & $60(0)$ & $15(-1)$ & $8.42 \mathrm{E} 4 \pm 3.88 \mathrm{E} 3$ & $1.36 \mathrm{E} 4 \pm 5.03 \mathrm{E} 2$ & $5.56 \mathrm{E} 3 \pm 2.60 \mathrm{E} 2$ \\
\hline 12 & Axial & $280(0)$ & $60(0)$ & $35(+1)$ & $1.02 \mathrm{E} 5 \pm 4.73 \mathrm{E} 3$ & $2.79 \mathrm{E} 4 \pm 9.17 \mathrm{E} 2$ & $1.43 \mathrm{E} 4 \pm 6.55 \mathrm{E} 2$ \\
\hline 13 & Axial & $280(0)$ & $30(-1)$ & $25(0)$ & $1.00 \mathrm{E} 5 \pm 2.91 \mathrm{E} 3$ & $1.88 \mathrm{E} 4 \pm 7.55 \mathrm{E} 2$ & $1.50 \mathrm{E} 4 \pm 6.95 \mathrm{E} 2$ \\
\hline 14 & Axial & $280(0)$ & $90(+1)$ & $25(0)$ & $9.80 \mathrm{E} 4 \pm 4.00 \mathrm{E} 3$ & $2.01 \mathrm{E} 4 \pm 8.50 \mathrm{E} 2$ & $1.45 \mathrm{E} 4 \pm 6.85 \mathrm{E} 2$ \\
\hline 15 & Center & $280(0)$ & $60(0)$ & $25(0)$ & $1.01 \mathrm{E} 5 \pm 3.95 \mathrm{E} 3$ & $1.89 \mathrm{E} 4 \pm 7.00 \mathrm{E} 2$ & $9.94 \mathrm{E} 3 \pm 4.75 \mathrm{E} 2$ \\
\hline 16 & Center & $280(0)$ & $60(0)$ & $25(0)$ & $1.01 \mathrm{E} 5 \pm 3.96 \mathrm{E} 3$ & $1.98 \mathrm{E} 4 \pm 8.02 \mathrm{E} 2$ & $1.04 \mathrm{E} 4 \pm 5.10 \mathrm{E} 2$ \\
\hline 17 & Center & $280(0)$ & $60(0)$ & $25(0)$ & $9.97 \mathrm{E} 4 \pm 4.01 \mathrm{E} 3$ & $1.93 \mathrm{E} 4 \pm 5.51 \mathrm{E} 2$ & $1.02 \mathrm{E} 4 \pm 5.00 \mathrm{E} 2$ \\
\hline 18 & Center & $280(0)$ & $60(0)$ & $25(0)$ & $1.02 \mathrm{E} 5 \pm 3.94 \mathrm{E} 3$ & $1.85 \mathrm{E} 4 \pm 6.03 \mathrm{E} 2$ & $9.85 \mathrm{E} 3 \pm 4.76 \mathrm{E} 2$ \\
\hline 19 & Center & $280(0)$ & $60(0)$ & $25(0)$ & $1.02 \mathrm{E} 5 \pm 3.59 \mathrm{E} 3$ & $1.83 \mathrm{E} 4 \pm 5.51 \mathrm{E} 2$ & $9.67 \mathrm{E} 3 \pm 4.70 \mathrm{E} 2$ \\
\hline 20 & Center & $280(0)$ & $60(0)$ & $25(0)$ & $1.04 \mathrm{E} 5 \pm 4.57 \mathrm{E} 3$ & $1.89 \mathrm{E} 4 \pm 8.50 \mathrm{E} 2$ & $9.45 \mathrm{E} 3 \pm 4.60 \mathrm{E} 2$ \\
\hline
\end{tabular}


Table 3

ANOVA evaluation for the response variables of AP.

\begin{tabular}{|c|c|c|c|c|c|c|}
\hline \multirow[t]{2}{*}{ Response variable } & \multicolumn{2}{|l|}{ COD } & \multicolumn{2}{|l|}{$\mathrm{TN}$} & \multicolumn{2}{|l|}{ TP } \\
\hline & SS & $\mathrm{P}$ & SS & $\mathrm{P}$ & SS & $\mathrm{P}$ \\
\hline Model & $2.495 E+09$ & $<0.0001$ & $5.295 E+08$ & $<0.0001$ & $2.869 \mathrm{E}+07$ & $<0.0001$ \\
\hline$X_{T}$ & $9.507 \mathrm{E}+07$ & 0.0006 & $2.856 \mathrm{E}+07$ & $<0.0001$ & $1.153 \mathrm{E}+07$ & 0.0001 \\
\hline$X_{R T}$ & $6.530 \mathrm{E}+06$ & 0.2239 & $2.601 E+06$ & 0.0066 & $5.497 \mathrm{E}+06$ & 0.0022 \\
\hline$X_{S R}$ & $1.298 \mathrm{E}+09$ & $<0.0001$ & $4.476 \mathrm{E}+08$ & $<0.0001$ & $1.602 \mathrm{E}+08$ & $<0.0001$ \\
\hline$X_{T}^{2}$ & $7.245 E+07$ & $<0.0015$ & $2.800 \mathrm{E}+06$ & 0.0053 & $2.192 \mathrm{E}+07$ & $<0.0001$ \\
\hline$X_{R T}^{2}$ & $1.051 \mathrm{E}+07$ & 0.1310 & $4.202 E+05$ & 0.1995 & $8.122 \mathrm{E}+05$ & $<0.0001$ \\
\hline$X_{S R}^{2}$ & $1.878 \mathrm{E}+08$ & $<0.0001$ & $7.863 E+06$ & 0.0001 & $9.052 \mathrm{E}+05$ & 0.2088 \\
\hline$X_{T} X_{R T}$ & $1.399 \mathrm{E}+07$ & 0.0869 & $3.200 E+07$ & $<0.0001$ & $1.983 \mathrm{E}+07$ & $<0.0001$ \\
\hline$X_{T} X_{S R}$ & $1.704 \mathrm{E}+08$ & $<0.0001$ & $7.220 \mathrm{E}+06$ & 0.0002 & $5.230 \mathrm{E}+07$ & 0.1477 \\
\hline$X_{R T} X_{S R}$ & $6.934 \mathrm{E}+06$ & 0.2111 & $8.015 E+04$ & 0.5622 & $5.954 \mathrm{E}+05$ & 0.1286 \\
\hline Residual & $3.884 \mathrm{E}+07$ & & $2.226 \mathrm{E}+06$ & & $3.298 E+05$ & \\
\hline Lack-of-fit & $2.644 \mathrm{E}+07$ & 0.2128 & $7.513 E+05$ & 0.7616 & $5.350 \mathrm{E}+05$ & 0.1679 \\
\hline Pure error & $1.240 \mathrm{E}+07$ & & $1.475 E+06$ & & $1.247 E+05$ & \\
\hline$R$ squared $\left(R^{2}\right)$ & 0.9847 & & 0.9918 & & 0.9874 & \\
\hline Adj. $R^{2}$ & 0.9709 & & 0.9890 & & 0.9760 & \\
\hline Predicted $R^{2}$ & 0.9073 & & 0.9371 & & 0.9267 & \\
\hline Adeq precision & 29.158 & & 62.823 & & 33.088 & \\
\hline
\end{tabular}

SS: sum of squares; $p$ : $p$ value for $F$ test; $R^{2}$ : determination coefficient; Adj. $R^{2}$ : adjusted $R^{2}$; Adeq precision: adequate precision.

The value of $R^{2}$ will increase when the number of variables in the model increases. Therefore, the adjusted $R$-squared value (Adj. $R^{2}$ ) is employed, which can decrease the $R^{2}$ value if insignificant factors are incorporated into the model. Table 3 shows that the values of adjusted $R^{2}$ for all models are well within the acceptable range of $R^{2} \geqq 0.8$. In addition, the values of predicted $R^{2}$ for all models are consistent with adjusted $R^{2}$. It indicates that all variables can be properly predicted by the second-order polynomial regression equations. Besides, the adequate precision is a parameter measuring the signal to noise ratio, and a corresponding value greater than 4 is desirable. Table 3 demonstrates that the values of adequate precision for all models are greater than 4 , which implies that all models can be used to guide the design.

Based on the ANOVA results, the developed models removing insignificant factors for COD, TN and TP are given in Eqs. (3)-(5), respectively, where $X_{T}, X_{R T}$, and $X_{S R}$ represent reaction temperature, retention time, and total solid ratio, respectively.

$$
\begin{aligned}
\mathrm{COD}= & 101,500-3083 \times X_{T}+11,392 \times X_{S R}+4616 \times X_{T} \times X_{S R} \\
& -5133 \times X_{T}^{2}-8265 \times X_{S R}^{2} \\
\mathrm{TN}= & 18,993-1690 \times X_{T}+510 \times X_{R T}+6690 \times X_{S R} \\
- & 2000 \times X_{T} \times X_{R T}-950 \times X_{T} \times X_{S R}-1009 \times X_{T}^{2}+1690 \times X_{S R}^{2}
\end{aligned}
$$

$\begin{aligned} \mathrm{TP}= & 101,110-1074 \times X_{T}-741 \times X_{R T}+4003 \times X_{S R} \\ & +1655 \times X_{T} \times X_{R T}-2685 \times X_{T}^{2}+4361 \times X_{R T}^{2}\end{aligned}$

$$
+1655 \times X_{T} \times X_{R T}-2685 \times X_{T}^{2}+4361 \times X_{R T}^{2}
$$

Attention should be given that the developed models are precise under specified conditions (e.g., using identical reactor and microalgae). However, the effect of operating conditions and their interactions on nutrient recovery of AP obtained from HTL processing of $C$. pyrenoidosa can be properly evaluated based on the proposed models.

\subsection{Effect of operating conditions on nutrients of $A P$}

\subsubsection{Chemical oxygen demand}

Fig. 1(a) presents the response surfaces of the chemical oxygen demand (COD) of the AP. Table 2 illustrates the COD was found to be from $6.27 \mathrm{E} 4 \pm 2.95 \mathrm{E} 3$ to $1.04 \mathrm{E} 5 \pm 4.57 \mathrm{E} 3 \mathrm{mg} / \mathrm{L}$, which is close to the COD (6.38E4-1.91E5 mg/L) reported for AP from HTL of Spirulina platensis (Jena et al., 2011b) and COD (3.3E4-7.0E4 mg/L) detected in AP from HTL of mixed-culture wastewater algae (Tommaso et al., 2015). The high values of COD indicate the presence of high content of organics that may pose an environmental problem for direct discharge of this byproduct. Therefore, as the $E^{2}$-Energy paradigm proposed, using the organic carbon in the AP for microalgae cultivation would be advantageous in terms of economic and technological feasibility.

Fig. 1(a) indicates that retention time did not greatly affect the COD concentration of the AP while the total solid ratio is the most influential factor. The COD of AP increased significantly with the increase of the total solid ratio from 15 to 25 wt.\%. Besides, with the further increase of the total solid ratio from 25 to $35 \mathrm{wt} . \%$, COD only slightly increased. However, according to the previous study (Gai et al., 2014), the carbon recovery of bio-crude oils increased slightly at lower total solid ratios (15-25 wt.\%) and increased greatly at higher ranges (25-35 wt.\%). It suggests that at lower total solid ratios, the carbon in the microalgae is likely partitioned to the AP and at higher total solid ratios, the carbon is favorably converted into the bio-crude oils during the HTL process. At higher total solid ratios (25-35wt.\%), the COD of AP slightly increased with the increased reaction temperature. However, at lower total solid ratios (15 wt.\%), a reverse trend could be observed. A possible explanation is that more carbons are converted into the gaseous products or solid residues when lower solid ratios of feedstock are applied during the HTL process.

\subsubsection{Total nitrogen}

Fig. 1(b) shows the response surfaces of total nitrogen (TN) in the AP. It can be seen that the AP contained a substantial amount of nitrogen ranging from $1.10 \mathrm{E} 4 \pm 3.06 \mathrm{E} 2$ to $3.17 \mathrm{E} 4 \pm 1.35 \mathrm{E} 3 \mathrm{mg} /$ L. Biller et al. (2012) analyzed the AP from HTL process of different feedstocks. It was observed that the total nitrogen ranged from 3000 to $8000 \mathrm{ppm}$. Scenedesmus and Chlorogloeopsis have the lowest amounts due to the low nitrogen content while Spirulina had the highest value due to its high protein (65\%) and nitrogen content. Similarly, the high nitrogen concentration in this study mainly results from the high content of proteins (71\%) in the $C$. pyrenoidosa.

In terms of the total nitrogen in the AP, Fig. 1(b) reveals that the effect of reaction temperature is closely linked to the retention time. Specifically, the concentration of total nitrogen gradually increased with the increment of reaction temperature at shorter retention time, while a reverse trend was observed at a longer time. The total nitrogen concentration increased with the 

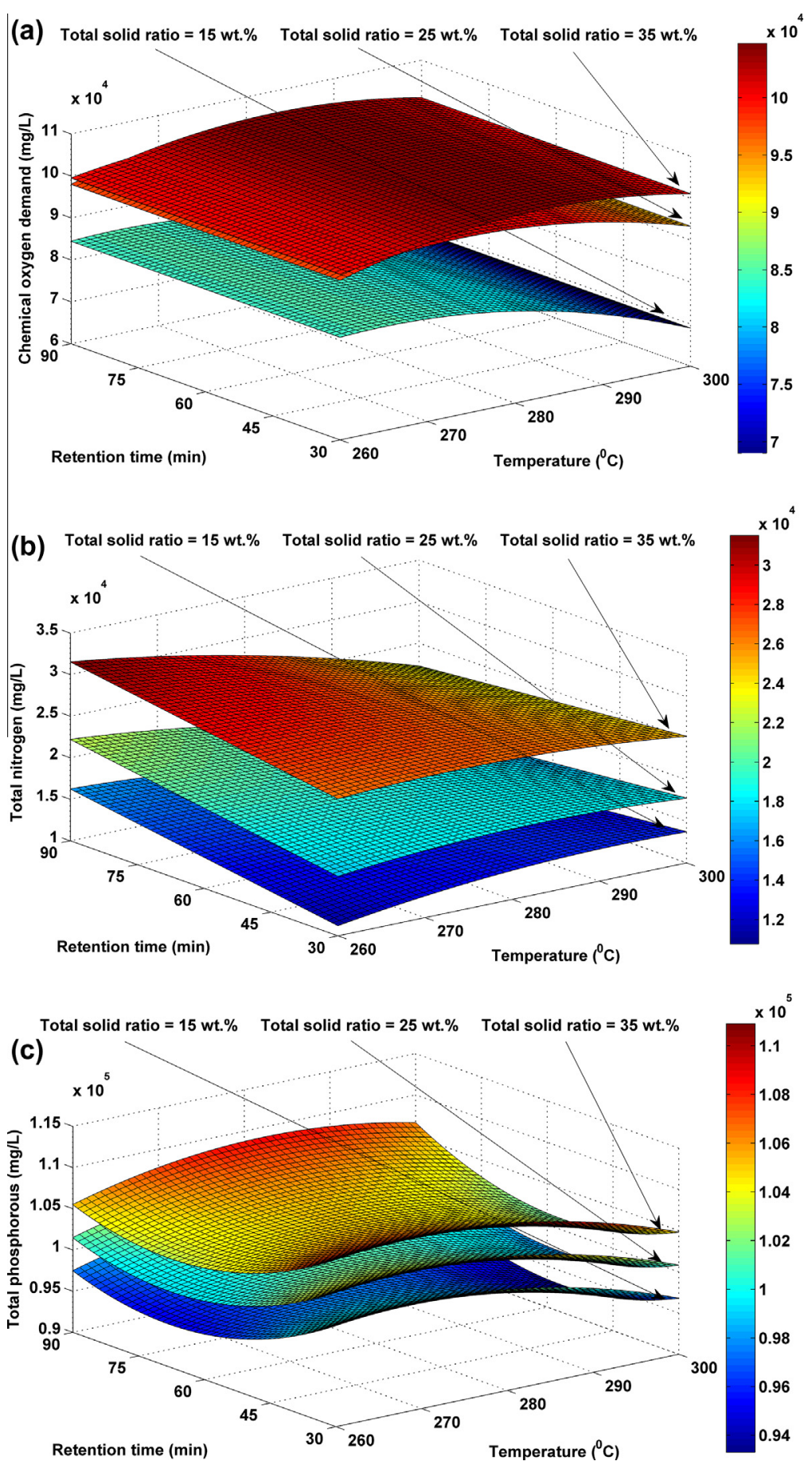

Fig. 1. Response surfaces analysis for AP via HTL of $C$. pyrenoidosa: (a) COD; (b) TN; (c) TP.

increment of retention time at lower temperatures, whereas it decreased slightly when prolonging the retention time at higher temperatures. The interactions of reaction temperature and retention time on AP was just opposite to that of bio-crude oils reported in the previous study (Gai et al., 2014). The variations of nitrogen content in bio-crude oils and AP are mainly due to the deamination of amino acids from degradation of protein under hydrothermal conditions (López Barreiro et al., 2013). It indicates that, at the mild liquefaction conditions, more nitrogen is distributed into the AP while, at boundary conditions, including either lower temperature with a shorter retention time or higher temperature with a longer retention time, more nitrogen may partition to the bio-crude oils instead of to the AP. Valdez et al. (2012) investigated the effect of operating conditions on product fractions from HTL of Nannochloropsis sp. It was observed that the total nitrogen in the AP generally increased with temperature at a shorter time of $20 \mathrm{~min}$, which verified one of the observations in this study. The total solid ratio was found to have the same effect on total nitrogen concentration of the AP compared with that of nitrogen recovery of bio-crude oils (Gai et al., 2014). It continuously increased with the increasing of the total solid ratio.

It is hoped that more nitrogen could be distributed to the AP because it means less nitrogen is retained in bio-crude oils, and the nitrogen in aqueous products could be recovered for cultivation of algae. Consequently, higher temperature with a shorter retention time or lower temperature with a longer retention time 
is recommended in this study. Previous studies (Zhou et al., 2013; Li et al., 2014) showed that the aqueous products from HTL process are mostly used to cultivate microalgae. The pretreatment of heavy dilutions are generally viewed as necessary for algae growth because the aqueous co-product of the HTL process contain high concentration of nutrients such as N and P. Biller et al. (2012) applied different dilution multiples of 50,200, 400 and 600 to the recycled process water from HTL process. They found that the optimum dilution is strain dependent but ranges between 200 and 400. Jena et al. (2011a) also concluded that heavy dilution is required to avoid the inhibition for algae growth. However, Garcia Alba et al. (2013) cultivated Desmodesmus sp. microalgae in recycled AP. They reported that the lack of essential (macro-/ micro-) nutrients other than $\mathrm{N}$ and $\mathrm{P}$ in $\mathrm{AP}$ is the main cause of growth reduction rather than toxicity due to insufficient AP dilution. Additionally, these nutrients such as $\mathrm{Mg}, \mathrm{K}$, and Na must be supplied upon AP recycling to avoid growth inhibition. Even if the nutrients in AP could be recycled back to the cultivation of algae, toxic compounds such as nitrogenous organic compounds (NOCs, e.g. pyridine and its derivatives) will be accumulated, which cannot be utilizable by the algae. Bacterial cultures have been verified to reduce the concentrations of these compounds in AP (Bajaj et al., 2008). For example, Nelson et al. (2013) investigated the microbial utilization of AP from HTL of microalgae Nannochloropsis culata. They found that AP could be recycled via microbial cultures with significantly less dilution than previously published methods. Therefore, further attention should be paid to efficient and economic utilization of AP, which is a key factor influencing the overall sustainability of $E^{2}$-Energy paradigm.

\subsubsection{Total phosphorus}

Fig. 1(c) demonstrates the response surfaces of TP of the AP and the TP was found to be from $5.44 \mathrm{E} 3 \pm 2.55 \mathrm{E} 2$ to $1.89 \mathrm{E} 4 \pm 9.15 \mathrm{E} 2 \mathrm{mg} / \mathrm{L}$. It can be clearly seen that the total solid ratio still has the greatest effect on the concentration of phosphate in the AP. It increased gradually when the total solid ratio increased from 15 to $35 \mathrm{wt} . \%$. Besides, the concentration of phosphate underwent a slight fall after a gradual rise with the increase of reaction temperature from $260^{\circ} \mathrm{C}$ to $300^{\circ} \mathrm{C}$, whereas it rose again after a fall with the increase of retention time from 30 to 90 min. Valdez et al. (2012) studied HTL of Nannochloropsis sp. They found that at a given reaction temperature (e.g., $250{ }^{\circ} \mathrm{C}$ or $300{ }^{\circ} \mathrm{C}$ ), the amount of phosphorus partitioned to the AP decreased first and then increased gradually with increasing retention time from 10 to $90 \mathrm{~min}$. The result showed similar trends to those obtained in the present study. Literatures (Peterson et al., 2008; Li et al., 2014) indicate that reaction temperature and retention time dramatically affected the distribution of intermediate products in HTL process. Kruse et al. (2005), Kruse et al. (2007) investigated the influence of proteins on the hydrothermal liquefaction of biomass. They found that some amino acids in aqueous products (e.g. alanine and glycine) increased firstly and then deceased with the increment of retention time. Additionally, amino acids may react with reducing sugar from hydrolysis of carbohydrates in microalgae, named Maillard reaction (Virág et al., 2013), to affect the concentration of phosphate in aqueous phase. For example, Aoki et al. (1997) reported that phosphate groups can be introduced to proteins by conjugation with glucose-6phosphate (G6P) through the Maillard reaction. Consequently, the specified reaction pathway of phosphorus-containing proteins in HTL processing of microalgae is recommended for further study. In addition, the phosphorus may be distributed to other phases such as solid residues besides the aqueous phase. Since the distribution of phosphorus during HTL process is probably affected by the metal composition in the feedstock (Yu, 2012), a comprehensive elemental balance of phosphorus for all product streams during the HTL process is needed in future study.

\subsection{GC-MS analysis and $p H$ values of $A P$}

Besides the nutrients, energy balance needs to be considered together for a proper evaluation of the feasibility of the $E^{2}$-Energy paradigm. Energy recovery (ER) and energy consumption ratio (ECR) are generally the two parameters evaluating the energy balance in most studies. ER of bio-crude oils for all the operation conditions was calculated in the previous study (Gai et al., 2014) and the results showed that the highest ER could be obtained at ERS1 (No. 12, ER: 69.54\%) and ERS2 (No. 10, ER: 67.86\%), while the lowest ER was brought by ERS3 (No. 2, ER: 36.88\%). It should be noted that the Run No. mentioned above is consistent with that of in Table 2.

As the co-product of HTL under the same operating conditions, the three aqueous samples were analyzed by GC/MS to identify the chemical compositions. The total chromatograms and the major chemical compositions (i.e. the relative percentage of peak areas over than $1 \%$ ) for the three samples of AP are available in the supplementary data. As shown in Fig. 2, the major chemical compositions are categorized into groups, including organic acids

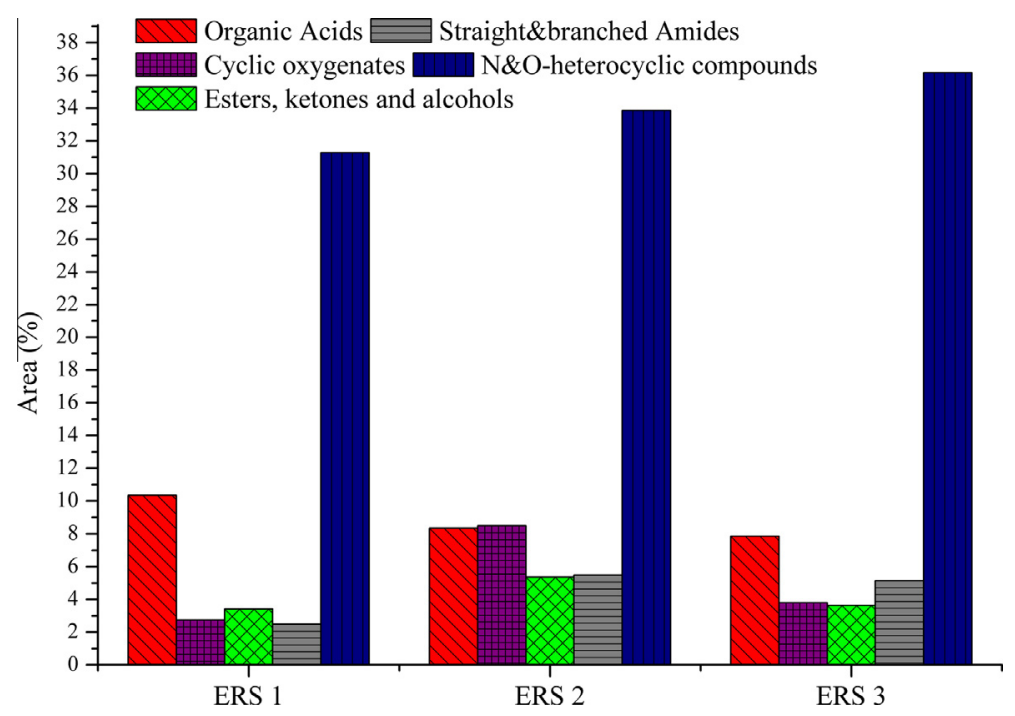

Fig. 2. Major groups of chemical compounds in AP. 
Table 4

$\mathrm{pH}$ values for the response variables of AP.

\begin{tabular}{|c|c|c|c|c|c|c|c|c|c|}
\hline Run No. & $\mathrm{T}\left({ }^{\circ} \mathrm{C}\right)$ & $\mathrm{RT}(\min )$ & SR (wt.\%) & $\mathrm{pH}$ & Run No. & $\mathrm{T}\left({ }^{\circ} \mathrm{C}\right)$ & $\mathrm{RT}(\min )$ & SR (wt.\%) & $\mathrm{pH}$ \\
\hline 1 & 260 & 30 & 15 & 7.79 & 11 & 280 & 60 & 15 & 7.77 \\
\hline 2 & 260 & 30 & 35 & 8.24 & 12 & 280 & 60 & 35 & 8.25 \\
\hline 3 & 260 & 90 & 15 & 7.85 & 13 & 280 & 30 & 25 & 8.10 \\
\hline 4 & 260 & 90 & 35 & 8.29 & 14 & 280 & 90 & 25 & 8.00 \\
\hline 5 & 300 & 30 & 15 & 7.87 & 15 & 280 & 60 & 25 & 8.05 \\
\hline 6 & 300 & 30 & 35 & 8.25 & 16 & 280 & 60 & 25 & 8.12 \\
\hline 7 & 300 & 90 & 15 & 7.92 & 17 & 280 & 60 & 25 & 8.09 \\
\hline 8 & 300 & 90 & 35 & 8.15 & 18 & 280 & 60 & 25 & 8.11 \\
\hline 9 & 260 & 60 & 25 & 7.94 & 19 & 280 & 60 & 25 & 8.13 \\
\hline 10 & 300 & 60 & 25 & 7.97 & 20 & 280 & 60 & 25 & 8.07 \\
\hline
\end{tabular}

(including fatty acid, etc), cyclic oxygenates (including phenols, phenol derivatives and fused ring compounds), esters, ketones and alcohols (including piperidine, pyrimidinone, etc), straight \& branched amides and $\mathrm{N} \& \mathrm{O}$-heterocyclic compounds. It should be noted that some compounds detected in this study contain more than one functional group are categorized into only one group.

Fig. 2 indicates that the saturated and unsaturated hydrocarbons were barely found in the aqueous sample, which are one of the main components detected in bio-crude oils in the previous study (Gai et al., 2014). Besides, it can be clearly seen that N\&Oheterocyclic compounds make up a larger percentage of the major chemical compositions, then accompanied by the organic acids. Among the three samples, the sample ERS 1 contained the most species of organic acids while ERS3 contained the most species of N\&O-heterocyclic compounds. Pham et al. (2013) also observed the same trend and could correlate the presence of N\&O-heterocyclic compounds to high toxicity. Tommaso et al. (2015) examined the anaerobic degradability of the aqueous product from HTL of mixed-culture algal biomass grown in a wastewater treatment system, and it was reported that as low was the area related to N\&O-heterocyclic compounds as high would be the anaerobic degradability.

NOCs affect the treatment or safely discharge of AP to the environment, and 2-piperidinone, 2-pyrrolidinone, and pyridine and its derivatives are commonly detected NOCs in HTL conversion of algae (Chen et al., 2014a,b; Lee et al., 2007). The same compounds could be detected in this work, including 2-piperidinone (RT. 26.96), 2-pyrrolidinone (RT. 25.31), 3-pyridinol (RT. 31.80) and 3pyridinol, 6-methyl-(RT. 31.51). Among the major NOCs observed in AP, ERS3 was observed to have the most species and concentrations of NOCs with methyl groups, such as 3-pyridinol, 6-methyl(RT. 31.51) and 2-imidazolidinone, 1,3-dimethyl-(RT.45.32). The compounds with two or more methyl groups were more toxic than those with one or no alkyl substitutions, which enhance the resistance of the compound to biological degradation (Schultz et al., 1978) and alters equilibrium partitioning of compounds between cell and medium (Schultz and Cajina-Quezada, 1982). Therefore, the AP under ERS3 may present a greater toxic potential to the environment compared to that of ERS1 and ERS2. However, the influences of operating parameters on the levels of toxicity in AP of HTL are recommended for further study because the interactions between different NOCs in AP may differ from individual compounds.

The $\mathrm{pH}$ values of all aqueous products in DOE were also measured and shown in Table 4. It indicated that the $\mathrm{pH}$ of the AP is more alkaline for all conditions ( $\mathrm{pH} 7.77-8.29)$ due to the large amounts of ammonium present according to the experimental results reported by Biller and Ross (2011), Biller et al. (2012) and the major composition of organic N-containing compounds reported by Garcia Alba et al. (2013), which was also verified by GC-MS in this study. Besides, it can be seen that the AP produced at higher total solid ratios (i.e. $35 \mathrm{wt} . \%$ ) are high $\mathrm{pH}$ products
$(\mathrm{pH}>8)$ while the AP obtained at lower total solid ratios (i.e., $15 \mathrm{wt} . \%)$ are low $\mathrm{pH}$ products $(\mathrm{pH}<8)$. It suggests that higher total solid ratios may promote the distribution of nitrogenous organics in AP instead of bio-crude oils, which is preferable to oil upgrading.

\section{Conclusions}

The AP from HTL of low-lipid microalgae were found to be high in carbon (COD: $6.27 \mathrm{E} 4 \pm 2.95 \mathrm{E} 3$ to $1.04 \mathrm{E} 5 \pm 4.57 \mathrm{E} 3 \mathrm{mg} / \mathrm{L}$ ), nitrogen (TN: $1.10 \mathrm{E} 4 \pm 3.06 \mathrm{E} 2$ to $3.17 \mathrm{E} 4 \pm 1.35 \mathrm{E} 3 \mathrm{mg} / \mathrm{L}$ ), phosphorus (TP: $5.44 \mathrm{E} 3 \pm 2.55 \mathrm{E} 2$ to $1.89 \mathrm{E} 4 \pm 9.15 \mathrm{E} 2 \mathrm{mg} / \mathrm{L}$ ). Total solid ratio was found to be the dominant factor affecting the concentration of nutrients in AP. GC-MS indicated that the AP contained a higher concentration of organic acids and lower concentration of N\&Oheterocyclic compounds when higher energy recoveries were obtained at optimized operating conditions $\left(280^{\circ} \mathrm{C}, 60 \mathrm{~min}\right.$, $35 \mathrm{wt} . \%$ and $\left.300^{\circ} \mathrm{C}, 60 \mathrm{~min}, 25 \mathrm{wt} . \%\right)$.

\section{Acknowledgements}

Authors gratefully acknowledge the China Scholarship Council and National Science and technology support program (2011YQ120039) for a financial support to the first author. The Department of Agricultural and Biological Engineering at University of Illinois at Urbana-Champaign provided the experiment facilities and expenses for the research. Authors also thank the fellow graduate students and researchers in the Bioenvironmental Engineering Division at University of Illinois at UrbanaChampaign for their kind assistance during the project.

\section{Appendix A. Supplementary data}

Supplementary data associated with this article can be found, in the online version, at http://dx.doi.org/10.1016/j.biortech.2014.10. 118.

\section{References}

Anastasakis, K., Ross, A.B., 2011. Hydrothermal liquefaction of the brown macroalga laminaria saccharina: effect of reaction conditions on product distribution and composition. Bioresour. Technol. 102, 4876-4883.

Aoki, T., Kitahata, K., Fukumoto, T., Sugimoto, Y., Ibrahim, H.R., Kimura, T., Kato, Y. Matsuda, T., 1997. Improvement of functional properties of $\beta$-lactoglobulin by conjugation with glucose-6-phosphate through the Maillard reaction. Food Res. Int. 30, 401-406.

Bajaj, M., Gallert, C., Winter, J., 2008. Biodegradation of high phenol containing synthetic wastewater by an aerobic fixed bed reactor. Bioresour. Technol. 99, 8376-8381.

Becker, E.W., 2007. Micro-algae as a source of protein. Biotechnol. Adv. 25, 207-210. Biller, P., Ross, A.B., 2011. Potential yields and properties of oil from the hydrothermal liquefaction of microalgae with different biochemical content. Bioresour. Technol. 102, 215-225.

Biller, P., Ross, A.B., Skill, S.C., Lea-Langton, A., Balasundaram, B., Hall, C., Riley, R. Llewellyn, C.A., 2012. Nutrient recycling of aqueous phase for microalgae cultivation from the hydrothermal liquefaction process. Algal Res. 1, 70-76. 
Cai, T., Park, S.Y., Li, Y., 2013. Nutrient recovery from wastewater steams by microalgae: status and prospects. Renewable Sustainable Energy Rev. 19, 360369.

Chen, W.-T., Zhang, Y., Zhang, J., Yu, G., Schideman, L.C., Zhang, P., Minarick, M., 2014a. Hydrothermal liquefaction of mixed-culture algal biomass from wastewater treatment system into bio-crude oil. Bioresour. Technol. 152, 130-139.

Chen, W.-T., Zhang, Y., Zhang, J., Schideman, L., Yu, G., Zhang, P., Minarick, M., 2014b. Co-liquefaction of swine manure and mixed-culture algal biomass from a wastewater treatment system to produce bio-crude oil. Appl. Energy 128, 209216.

Gai, C., Zhang, Y., Chen, W.-T., Zhang, P., Dong, Y., 2013. Thermogravimetric and kinetic analysis of thermal decomposition characteristics of low-lipid microalgae. Bioresour. Technol. 150, 139-148.

Gai, C., Zhang, Y., Chen, W.-T., Zhang, P., Dong, Y., 2014. Energy and nutrient recovery efficiencies in biocrude oil produced via hydrothermal liquefaction of Chlorella pyrenoidosa. RSC Adv. 4, 16958-16967.

Garcia Alba, L., Torri, C., Samori, C., van der Spek, J., Fabbri, D., Kersten, S.R.A., 2012 Hydrothermal treatment (HTT) of microalgae: evaluation of the process as conversion method in an algae biorefinery concept. Energy Fuel 26, 642-657.

Garcia Alba, L., Torri, C., Fabbri, D., Kersten, S.R.A., Brilman, D.W.F., 2013. Microalgae growth on the aqueous phase from hydrothermal liquefaction of the same microalgae. Chem. Eng. J. 228, 214-223.

Jena, U., Vaidyanathan, N., Chinnasamy, S., Das, K.C., 2011a. Evaluation of microalgae cultivation using recovered aqueous co-product from thermochemical liquefaction of algal biomass. Bioresour. Technol. 102, 3380 3387.

Jena, U., Das, K.C., Kastner, J.R., 2011b. Effect of operating conditions of thermochemical liquefaction on biocrude production from Spirulina platensis. Bioresour. Technol. 102, 6221-6229.

Kruse, A., Krupka, A., Schwarzkopf, V., Gamard, C., Henningsen, T., 2005. Influence of proteins on the hydrothermal gasification and liquefaction of biomass. 1 . Comparison of different feedstocks. Ind. Eng. Chem. Res. 44, 3013-3020.

Kruse, A., Maniam, P., Spieler, F., 2007. Influence of proteins on the hydrotherma gasification and liquefaction of biomass. 2. Model compounds. Ind. Eng. Chem. Res. 46, 87-96.

Lee, W., Westerhoff, P., Croue, J.P., 2007. Dissolved organic nitrogen as a precursor for chloroform. Dichloroacetonitrile, n-nitrosodimethylamine, and trichloronitromethane. Environ. Sci. Technol. 41, 5485-5490.

Li, H., Liu, Z., Zhang, Y., Li, B., Lu, H., Duan, N., Liu, M., Zhu, Z., Si, B., 2014. Conversion efficiency and oil quality of low-lipid high-protein and high-lipid low-protein microalgae via hydrothermal liquefaction. Bioresour. Technol. 154, 322-329.

López Barreiro, D., Prins, W., Ronsse, F., Brilman, W., 2013. Hydrotherma liquefaction (HTL) of microalgae for biofuel production: state of the art review and future prospects. Biomass Bioenergy 53, 113-127.
Nelson, M., Zhu, L., Thiel, A., Wu, Y., Guan, M., Minty, J., Wang, H.Y., Lin, X.N., 2013. Microbial utilization of aqueous co-products from hydrothermal liquefaction of microalgae Nannochloropsis oculata. Bioresour. Technol. 136, 522-528.

Peterson, A.A., Vogel, F., Lachance, R.P., Fröling, M., Antal Jr., M.J., Tester, J.W., 2008. Thermochemical biofuel production in hydrothermal media: a review of suband supercritical water technologies. Energy Environ. Sci. 1, 32-65.

Pham, M., Schideman, L., Scott, J., Rajagopalan, N., Plewa, M.J., 2013. Chemical and biological characterization of wastewater generated from hydrothermal liquefaction of Spirulina. Environ. Sci. Technol. 47, 2131-2138.

Ross, A.B., Biller, P., Kubacki, M.L., Lea-Langton, H.L., Jones, J.M., 2010. Hydrothermal processing of microalgae using alkali and organic acids. Fuel 89, 2234-2243.

Scholz, M.J., Riley, M.R., Cuello, J.L., 2013. Acid hydrolysis and fermentation of microalgal starches to ethanol by the yeast Saccharomyces cerevisiae. Biomass Bioenergy 48, 59-65.

Schultz, T.W., Cajina-Quezada, M., 1982. Structure toxicity relationships of selected nitrogenous heterocyclic compounds II. Dinitrogen molecules. Environ. Contam. Toxicol. 1982 (11), 353-361.

Schultz, T.W., Kyte, L.M., Dumont, J.N., 1978. Structure-toxicity correlations of organic contaminants in aqueous coal conversion effluents. Environ. Contam. Toxicol. 7, 457-463.

Tommaso, G., Chen, W.-T., Li, P., Schideman, L., Zhang, Y., 2015. Chemical characterization and anaerobic biodegradability of hydrothermal liquefaction aqueous products from mixed-culture wastewater algae. Bioresour. Technol. $178,139-146$

Valdez, P.J., Nelson, M.C., Wang, H.Y., Lin, X.N., Savage, P.E., 2012. Hydrothermal liquefaction of Nannochloropsis sp.: systematic study of process variables and analysis of the product fractions. Biomass Bioenergy 46, 317-331.

Virág, D., Kiss, A., Forgó, P., Csutorás, C., Molnár, S., 2013. Study on Maillard-reaction driven transformations and increase of antioxidant activity in lysine fortified biscuits. Microchem. J. 107, 172-177.

Yu, G., Zhang, Y., Schideman, L., Funk, T., Wang, Z., 2011a. Distributions of carbon and nitrogen in the products from hydrothermal liquefaction of low-lipid microalgae. Energy Environ. Sci. 4, 4587-4595.

Yu, G., Zhang, Y., Schideman, L., Funk, T., Wang, Z., 2011b. Hydrothermal liquefaction of low lipid content microalgae into bio-crude oil. Trans. ASABE 54, 239-246.

Yu, G., 2012. Hydrothermal liquefaction of low-lipid microalgae to produce biocrude oil (PhD dissertation). Agricultural and Biological Engineering. University of Illinois at Urbana-Champaign, Urbana, IL.

Zhou, Y., Schideman, L., Yu, G., Zhang, Y., 2013. A synergistic combination of algal wastewater treatment and hydrothermal biofuel production maximized by nutrient and carbon recycling. Energy Environ. Sci. 6, 3765-3779. 